CLINICAL STUDY

\title{
Bone density and metabolism in subjects with microdeletion of chromosome 22q11 (del22q11)
}

\author{
Stefano Stagi ${ }^{1}$, Elisabetta Lapi ${ }^{2}$, Eleonora Gambineri ${ }^{1}$, Cristina Manoni $^{1}$, Maurizio Genuardi $^{2}$, Gloria Colarusso $^{1}$, \\ Camilla Conti ${ }^{1}$, Francesco Chiarelli ${ }^{3}$, Maurizio de Martino ${ }^{1}$ and Chiara Azzari ${ }^{1}$ \\ ${ }^{1}$ Paediatric Endocrinology Unit, Department of Paediatrics, ${ }^{2}$ Genetics and Molecular Medicine Unit, Anna Meyer Children's Hospital, University of \\ Florence, Viale Pieraccini 24, 50139 Florence, Italy and ${ }^{3}$ Department of Paediatrics, University of Chieti, via dei Vestini 5, 66100 Chieti, Italy \\ (Correspondence should be addressed to S Stagi; Email: stefano.stagi@yahoo.it)
}

\begin{abstract}
Introduction: Although hypoparathyroidism with hypocalcaemia is one of the most frequent clinical features of monoallelic microdeletion of chromosome 22q11 (22q11DS), bone mass and metabolism have not yet been assessed in these patients.

Design: This study aimed to evaluate bone mass and metabolism in a cohort of patients, both children and adults, with 22q11DS.

Methods: In twenty-eight patients with 22q11DS (median age 12.5, range 6.1-42.8 years), serum levels of ionised and total calcium, phosphate, parathyroid hormone (PTH), 25-hydroxyvitamin D, 1,25-dihydroxyvitamin D, osteocalcin and bone-specific alkaline phosphatase (BSAP), and urinary deoxypyridinoline concentrations were evaluated. In these patients, bone mineral density (BMD) was evaluated by dual-energy X-ray absorptiometry (DXA) examination, and volumetric BMD (bone mineral apparent density (BMAD)) was calculated.

The data obtained from paediatric and adult patients were compared with two age-, sex- and body sizematched healthy subject control groups.

Results: Patients with 22q11DS showed a reduced BMAD Z-score compared with controls $(P<0.001)$. These patients also had significantly lower ionised $(P<0.001)$ and total calcium $(P<0.05)$ levels as well as lower PTH levels $(P<0.05)$, compared with the controls. In particular, children and young patients with 22q11DS had significantly lower serum osteocalcin levels $(P<0.001)$, BSAP levels $(P<0.001)$ and urinary deoxypyridinoline concentrations $(P<0.001)$ than controls. These results were not confirmed in adults.

Finally, patients with hypoparathyroidism and/or hypocalcaemia at the time of the study showed significantly lower ionised $(P<0.001)$ and total calcium levels $(P<0.001)$, PTH levels $(P<0.05)$, BSAP levels $(P<0.001)$, osteocalcin levels $(P<0.001)$ and urinary deoxypyridinoline concentrations $(P<0.001)$, compared with patients without hypoparathyroidism and/or hypocalcaemia. Nonetheless, the BMAD Z-score did not show substantial differences between these two groups.

Conclusions: Subjects with 22q11DS have a significant reduction in bone mass that appears to be more severe in adults who have already attained peak bone mass than in children who are still growing. Therefore, we suggest a close monitoring of bone mass and metabolism in 22q11DS patients.
\end{abstract}

European Journal of Endocrinology 163 329-337

\section{Introduction}

Microdeletion of chromosome 22q11.2 (22q11DS) is a relatively common genetic condition, occurring with an incidence of 1 out of 4000 live births (1). It is characterised by a highly heterogeneous phenotypic expression, and more than 100 different phenotypes have been described; the most commonly occurring phenotypes are DiGeorge syndrome, velocardiofacial syndrome (VCFS) and conotruncal anomaly face syndrome (1).

As a consequence of the microdeletion, there is a congenital failure in the development of the derivatives of various pharyngeal arches and pouches (2), with highly variable clinical features (3) encompassing congenital cardiac defects, hypocalcaemia, immunodeficiency from thymic hypoplasia, palate anomalies and velopharyngeal dysfunction, cognitive impairment and minor facial dismorphisms (2).

Hypocalcaemia is the most frequent feature of 22q11DS, occurring in nearly $60 \%$ of the patients; this condition is invariably due to hypoparathyroidism, which is caused by the aplasia or hypoplasia of the parathyroid glands $(3,4)$. Usually hypoparathyroidism manifests itself during the neonatal period (5); however, late-onset appearance of symptomatic 
hypocalcaemia has also been reported in adolescence and adulthood (5).

Dual-energy X-ray absorptiometry (DXA) is one of the mainstays in the evaluation of bone diseases and disorders, and is the most widely used technique for measuring bone mineral content (BMC) as well as bone mineral density (BMD) in children because of its low cost, accessibility and ease of use (6).

As BMD measurements are influenced by bone size and short children will have a lower BMD than their age-matched peers with normal stature, bone mineral apparent density (BMAD) must be calculated $(7,8)$. Many previous studies that used DXA have reported reduced $\mathrm{BMD}$ measurements for patients with short stature and/or genetic syndromes associated with short stature; this result could be explained by reduced height because BMD is a measurement of area and these patients have reduced height, which negatively affects their BMD values (9-13).

In any case, there is little data available about bone metabolism and mass in these patients; therefore, the purpose of this study was to evaluate BMAD and bone metabolism parameters in a cohort of patients with 22q11DS.

\section{Subjects and methods}

We have studied a cohort of 28 patients with 22q11DS (19 females and 9 males; median age 12.5, range 6.1-42.8 years), containing both children (17 patients, 11 females and 6 males; median age 9.6 years; range 6.1-16.6 years) and adults (11 patients, 8 females and 3 males; median age 26 years; range $16.75-42.8$ years) who were recruited from July to October 2006 at Meyer Children's Hospital in Florence, Italy.

Ethical approval was obtained from the ethics committee of the Meyer Children's Hospital. Written informed consent was obtained from parents or patients according to age and ability to assent.

\section{Case definition and study protocol}

Between 1994 and 2004, a diagnosis of 22q11DS was obtained for all subjects at the Genetics and Molecular Medicine Unit of the A. Meyer Children's Hospital using a fluorescence in situ hybridisation (FISH) test. Of these, 26 patients showed a de novo deletion at the $22 \mathrm{q} 11.2$ level, whereas 2 patients (mother and child) showed a familial deletion. All of the patients showed typical $22 \mathrm{q} 11.2$ microdeletions that were $\sim 3 \mathrm{Mb}$ in size.

Based on the literature concerning the major clinical features of patients with 22q11DS, the presence or absence of the following features in each patient was recorded: congenital cardiac defects; palate anomalies, including cleft palate or velopharyngeal insufficiency; craniofacial dysmorphisms; congenital hypocalcaemia and hypoparathyroidism; thymic hypoplasia or a history of recurrent infections; and cognitive/learning difficulties and behavioural abnormalities.

Participants or their parents were asked to fill out a questionnaire, which was then reviewed by the medical staff during the baseline examination. The questions related to current and past medications, especially vitamin $\mathrm{D}$ and/or calcium intake, familial and personal bone fracture history, dietary habits and physical activity.

For all subjects, data on height, height velocity, pubertal staging, weight and body mass index (BMI) were collected and, when appropriate, bone age was determined. According to their growth velocity, pubertal staging and/or bone age, the patients were divided into two groups: i) paediatrics (patients that had not reached the adult height) and ii) adults (patients that had reached adult height).

The investigation consisted of a fasting blood sampling that was analysed to determine the following measurements: serum concentrations of creatinine, albumin, calcium (total and ionised), phosphate, 25-hydroxyvitamin D (25[OH]D) and 1,25-dihydroxyvitamin $\mathrm{D}\left(1,25[\mathrm{OH}]_{2} \mathrm{D}\right)$; plasma levels of parathyroid hormone (PTH); and markers of bone formation (bonespecific alkaline phosphatase (BSAP) and osteocalcin) and bone resorption (urinary deoxypyridinoline).

All patients under observation were free of congenital or acquired bone disease, and we excluded all subjects who were using any drug known to affect bone turnover markers at the time of the study. Furthermore, we only considered 22q11DS patients who had not been using calcium supplementation or vitamin $\mathrm{D}$ treatment for at least 1 year prior to the beginning of the study.

Using an activity questionnaire, physical activity was assessed with a modified activity score composed of the scores for sports/leisure activities $(0,<2$ or $>2 \mathrm{~h} /$ week), as previously described (14).

Calcium dietary intake was assessed with the semiquantitative validated food frequency questionnaire (14). Selection of items was based on the food composition diet, frequency of use and relative importance of food items as a calcium source. The questionnaire included the following food items: milk and dairy products, including calcium-enriched items such as yoghurt, cheese and chocolate. Items such as eggs, meat, fish, cereals, bread, vegetables and fruits were also included.

The data obtained were compared with two age-, sexand body size-matched healthy subject control groups for paediatric (67 subjects, 46 females and 21 males, mean age $9.9 \pm 3.1$ years) and adult patients (81 subjects, 58 females and 23 males, mean age $25.1 \pm 5.9$ years $)$.

For every patient, we selected four to seven control subjects that matched the following criteria: age \pm 12 months, height $\pm 10 \mathrm{~cm}$, weight $\pm 2.0 \mathrm{~kg}$ and equivalent pubertal stage. Controls were randomly selected from a population survey of healthy Caucasian 
inhabitants in Tuscany with no rheumatic, endocrine or metabolic diseases, some of whom were seen for non-inflammatory musculoskeletal complaints at the Paediatric Rheumatology Unit of our hospital. Informed consent was obtained from all subjects and/or parents.

\section{Study and laboratory methods}

Height was measured using a wall-mounted stadiometer, and weight was measured to the nearest $0.1 \mathrm{~kg}$. All of the measurements were carried out by the same trained staff members. The coefficient of variation $(\mathrm{CV})$ values were $<1 \%$ for these measurements.

BMI was calculated as weight divided by height squared $\left(\mathrm{kg} / \mathrm{m}^{2}\right)$. Age-related reference values for height, bone age and BMI were obtained from a wide sample of Italian children (15).

Bone age, when appropriate, was evaluated through radiographs of the left hand and wrist, and then calculated according to the Greulich \& Pyle method (16). We considered it unnecessary to perform radiographs when the subjects had reached adult height (growth velocity $<1 \mathrm{~cm} /$ year with complete pubertal development).

Height, bone age and BMI were normalised for chronological age by conversion to SDS. SDS values were calculated according to the following formula: (patient value-mean of age-related reference value)/s.D. of the age-related reference value.

Pubertal staging was carried out according to Tanner \& Whitehouse's criteria (17).

All laboratory measurements were performed on blood samples collected after overnight fasting and on a 24-h urinary collection. Serum levels of calcium, phosphate, creatinine and albumin were measured in all samples by the standard autoanalyser method routinely used for daily practice.

Normal serum concentrations of total calcium are 2.2-2.7 $\mathrm{mmol} / \mathrm{l}$ for children and $2.2-2.6 \mathrm{mmol} / \mathrm{l}$ for adults. Normal blood concentrations of phosphate are $1.4-1.7 \mathrm{mmol} / \mathrm{l}$ from 2 to 12 years and 1.09$1.4 \mathrm{mmol} / \mathrm{l}$ from 12 to 16 years of age; the normal adult range is $0.8-1.45 \mathrm{mmol} / \mathrm{l}$.

Blood-ionised calcium concentrations were measured within a few minutes of sampling with an ICA Kit (McLendon Clinical Laboratories, Chapel Hill, NC, USA). The normal range is $1.18-1.32 \mathrm{mmol} / \mathrm{l}$.

Serum intact (1-84) PTH concentrations were measured with a two-site chemiluminescent immunometric assay (Nichols Institute Diagnostics, San Juan Capistrano, CA, USA). The inter-assay CV was $10 \%$. The normal range is given as $0.9-5.4 \mathrm{pmol} / \mathrm{l}$.

Serum $25[\mathrm{OH}] \mathrm{D}$ and $1,25[\mathrm{OH}]_{2} \mathrm{D}$ were determined according to a competitive binding protein assay (Nichols Diagnostics). The inter-assay CV was $8 \%$. The normal range is stated as $9.2-45.2 \mathrm{ng} / \mathrm{ml}$ for $25[\mathrm{OH}] \mathrm{D}$ and $19.9-67 \mathrm{pg} / \mathrm{ml}$ for $1,25[\mathrm{OH}]_{2} \mathrm{D}$.
A commercially available RIA kit was used to measure serum osteocalcin levels (CIS Diagnostici S.p.A., Tronzano Vercellese, Italy). The sensitivity of the method was $0.50 \mathrm{ng} / \mathrm{ml}$.

Urinary deoxypyridinoline concentrations were measured by high-resolution chromatography in a fluid environment (Medical System, Genova, Italy). Deoxypyridinoline values were expressed in $\mathrm{nM}$ for $\mathrm{mM}$ of nocturnal 12-h urinary creatinine. The intra- and inter-assay CV of RIA and IRMA methods were $<9.8 \%$.

The serum level of BSAP was measured by immunoassay (Metra Biosystems, Mountain View, CA, USA) with a sensitivity of $0.7 \mathrm{U} / \mathrm{l}$ and a $\mathrm{CV}$ of $3.9-5.8 \%$.

In all the patients, lymphocyte subpopulations were measured by flow cytometry (FACScan cytofluorimeter; Becton Dickinson, San José, CA, USA) with the use of fluorescein- or phycoerythrin-labelled human MABs (anti-CD3, anti-CD19, anti-CD3 $+4+$, anti-CD3 $+8+$ and anti-CD3 $-16+56+$; Becton Dickinson).

In all patients, BMC $(\mathrm{g})$ and $\mathrm{BMD}\left(\mathrm{g} / \mathrm{cm}^{2}\right)$ of the lumbar spine (L1-L4) were measured by DXA (Delphi-A System, Hologic, Inc., Waltham, MA, USA).

BMD was expressed as Z-scores (that is, the difference between the value of the patient and the normal value for age divided by the S.D. of the normal patient group). Average BMD values for $\mathrm{L} 2-\mathrm{L} 4$ were used for calculations.

The DXA instrument's software calculates BMD by dividing the BMC by the area of the projection surface of bones (areal BMD; $\mathrm{g} / \mathrm{cm}^{2}$ ). This does not take into account the actual bone volume, which is strictly related to body size (weight and height), a particularly important aspect when evaluating a growing skeleton. Different methods of correction have been proposed for pathologies where a smaller-than-normal body size may be present $(7,8)$, such as 22q11DS (18).

Therefore, for estimation of the respective volumetric density, which is usually referred to as the BMAD, the following formula from Kröger et al. (8) was used:

$$
\begin{aligned}
\mathrm{BMAD}= & \mathrm{BMD}_{\mathrm{L} 2-\mathrm{L} 4} \times\left(\frac{4}{(\pi \times \text { width })}\right), \\
& \text { expressed in }\left(\mathrm{g} / \mathrm{cm}^{3}\right)
\end{aligned}
$$

Bone width was the real mean width of these vertebrae. It was calculated from the dimensions that were manually read off with the ruler from the picture of the spine that was included in the printout of the results of each measurement. If $A 2, A 3$ and $A 4$ are the real projected areas of the respective vertebrae, $h$ is their depicted total height and $b$ is their depicted mean width, then

Bone width $=\sqrt{\frac{A 2+A 3+A 4}{h} \times b}$

Each measurement was taken along the vertebral body at three locations (upper, middle and lower parts of 
the vertebra) by the same researcher, and the mean from these measurements was used; the intra-observer CV was $1.0 \%$.

This model was validated by in vivo volumetric data obtained from magnetic resonance imaging of the lumbar vertebrae (19).

Also, patients' BMADs were expressed as Z-scores (that is, the difference between the value of the patient and the normal value for age divided for s.D. of the normal patients group).

In adults, DXA measurements are usually reported as T-scores (number of s.D.s from the mean BMD of a reference group of normal gender-matched individuals in the age range (third decade) during which BMD peaks). However, T-scores are not applicable for individuals under the age of 20 years; therefore, for comparisons and correlations between groups, all measurements of BMAD were reported as age- and gender-matched Z-scores.

Quality control was regularly performed by using a phantom to ensure the reliability of the densitometer. All BMD measurements were performed by the same operator and were carried out on the same DXA instrument using a standardised protocol of measurement. The CV was $0.64 \%$ for BMC and $1.0 \%$ for lumbar spine BMD and BMAD.

\section{Statistical analysis}

Statistical analyses were performed using SPSSX (SPSSX Inc., Chicago, IL, USA). Summaries of continuous variables are given as mean \pm s.D. or median and range, depending on whether the data were normally distributed or not. To compare differences, we used the Student's $t$-test and Mann-Whitney $U$ test, depending on the distribution of the analysed variable. The $\chi^{2}$-test and Fisher's exact test were used to examine associations between dichotomous variables. Spearman's (rank) correlation test was used to determine the correlation coefficients. A multiple stepwise regression was used to determine the variables (age (years), sex (M:F), serum PTH concentrations, ionised and total calcium, phosphate, $25[\mathrm{OH}] \mathrm{D}$ and $1,25[\mathrm{OH}]_{2} \mathrm{D}$ levels, serum osteocalcin levels, urinary deoxypyridinoline concentrations, quantitative assessment of physical activity (h/week), calcium intake (mg/day) and BSAP levels) that may correlate independently with BMD and BMAD Z-score values. $P$ values $<0.05$ were considered statistically significant.

\section{Results}

The main auxological features and laboratory characteristics of the patients are summarised in Tables 1 and 2 .

No statistically significant differences were found between our group of patients with 22q11DS and the control group regarding BMI SDS, history of fractures
Table 1 Baseline characteristics of 22q11DS patients and controls.

\begin{tabular}{|c|c|c|c|}
\hline & 22q11DS & Controls & $P$ \\
\hline \multicolumn{4}{|l|}{ Age (years) } \\
\hline Children $(n)$ & $9.5 \pm 3.2(17)$ & $9.9 \pm 3.1(67)$ & NS \\
\hline Adults $(n)$ & $27.0 \pm 8.5(11)$ & $25.1 \pm 5.9(81)$ & NS \\
\hline Height (SDS) & $-0.6 \pm 0.7$ & $-0.1 \pm 0.7$ & $<0.05$ \\
\hline Children & $-0.5 \pm 0.7$ & $-0.0 \pm 0.8$ & $<0.05$ \\
\hline Adults & $-0.7 \pm 0.8$ & $-0.2 \pm 0.6$ & $<0.05$ \\
\hline BMI (SDS) & $0.0 \pm 0.7$ & $-0.2 \pm 1.0$ & NS \\
\hline Children & $0.1 \pm 0.7$ & $-0.2 \pm 0.8$ & NS \\
\hline Adults & $-0.2 \pm 0.6$ & $-0.2 \pm 0.6$ & NS \\
\hline Bone age (SDS) & $-0.1 \pm 1.3$ & - & - \\
\hline \multicolumn{4}{|l|}{$\begin{array}{l}\text { Calcium intake } \\
\text { (mg/day) }\end{array}$} \\
\hline Children & $790 \pm 260$ & $825 \pm 302$ & NS \\
\hline Adults & $725 \pm 210$ & $760 \pm 195$ & NS \\
\hline $\begin{array}{l}\text { Serum intact PTH } \\
(\mathrm{pmol} / \mathrm{l})\end{array}$ & $2.41 \pm 1.22$ & $3.15 \pm 1.41$ & $<0.05$ \\
\hline Children & $2.37 \pm 1.36$ & $3.27 \pm 1.01$ & $<0.01$ \\
\hline Adults & $2.51 \pm 0.97$ & $3.08 \pm 1.52$ & $<0.05$ \\
\hline \multicolumn{4}{|l|}{ Osteocalcin (ng/ml) } \\
\hline Children & $28.62 \pm 4.71$ & $92.18 \pm 20.83$ & $<0.001$ \\
\hline Adults & $7.53 \pm 3.12$ & $8.54 \pm 2.55$ & NS \\
\hline \multicolumn{4}{|l|}{$\begin{array}{c}\text { Serum BSAP } \\
\text { levels (U/I) }\end{array}$} \\
\hline Children & $57.9 \pm 19.5$ & $101.8 \pm 28.5$ & $<0.001$ \\
\hline Adults & $13.3 \pm 10.5$ & $16.5 \pm 8.6$ & NS \\
\hline $\begin{array}{l}\text { Serum } 25(\mathrm{OH}) \\
\quad \text { vitamin } \mathrm{D}(\mathrm{ng} / \mathrm{ml})\end{array}$ & $35.1 \pm 17.2$ & $30.5 \pm 15.6$ & NS \\
\hline Children & $32.0+16.3$ & $28.7+14.0$ & NS \\
\hline Adults & $39.5 \pm 18.3$ & $33.8 \pm 14.5$ & NS \\
\hline $\begin{array}{r}\text { Serum } 1,25(\mathrm{OH})_{2} \\
\quad \text { vitamin } \mathrm{D}(\mathrm{pg} / \mathrm{ml})\end{array}$ & $51.9 \pm 16.1$ & $42.0 \pm 20.7$ & $<0.05$ \\
\hline Children & $46.8 \pm 14.6$ & $41.2 \pm 18.0$ & NS \\
\hline Adults & $54.5+17.9$ & $43.0+19.2$ & NS \\
\hline \multicolumn{4}{|c|}{$\begin{array}{l}\text { Urinary } \\
\text { deoxypyridinoline } \\
\text { (nM/mM creatinine) }\end{array}$} \\
\hline Children & $16.64+11.53$ & $42.17+14.76$ & $<0.001$ \\
\hline Adults & $9.43 \pm 3.22$ & $13.67 \pm 4.78$ & NS \\
\hline
\end{tabular}

and calcium intake; however, a statistically significant difference was found regarding height $(-0.6 \pm 0.7$ vs $-0.1 \pm 0.7, P<0.05$; Table 1).

In particular, 3 ( 1 male and 2 females; 10.7\%) of 28 participants had experienced a fracture before the study. All were post-traumatic fractures, and there were no statistically significant differences with respect to controls $(9.9 \%)$. In addition, no significant differences were found in calcium intake between 22q11DS patients and controls (children $790 \pm 260$ vs $825 \pm 302 \mathrm{mg} /$ day; adults $725 \pm 210$ vs $760 \pm 195 \mathrm{mg} /$ day; $P=\mathrm{NS}$ ).

Patients with 22q11DS showed a reduced BMAD Z-score compared with controls $(-0.90 \pm 1.01$ vs $0.01 \pm 0.87 ; P<0.001$; Fig. 1a); this result was also evident when the subjects were divided into two groups of either paediatric $(-0.66 \pm 0.98$ vs $0.01 \pm 0.81$; $P<0.05$; Fig. $1 b)$ or adult patients $(-1.51 \pm 0.85$ vs $-0.02 \pm 0.76 ; P<0.001$; Fig. 1c).

Patients with 22q11DS showed significantly lower ionised $(0.99 \pm 0.07$ vs $1.24 \pm 0.04 \mathrm{mmol} / \mathrm{l} ; P<0.001)$ and total calcium levels $(2.29 \pm 0.13$ vs 2.53 $\pm 0.13 \mathrm{mmol} / \mathrm{l} ; \mathrm{P}<0.05)$ compared with the controls, 


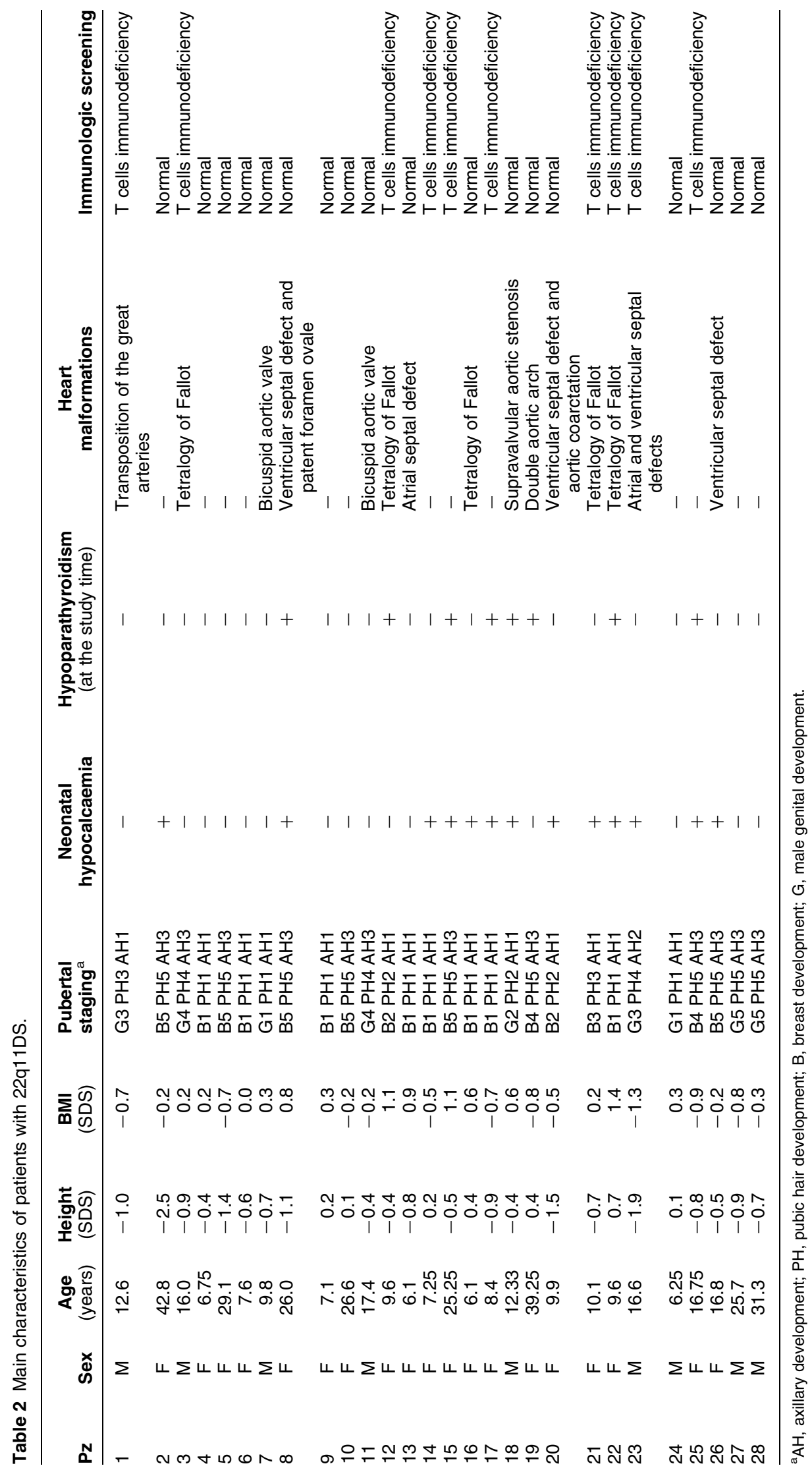



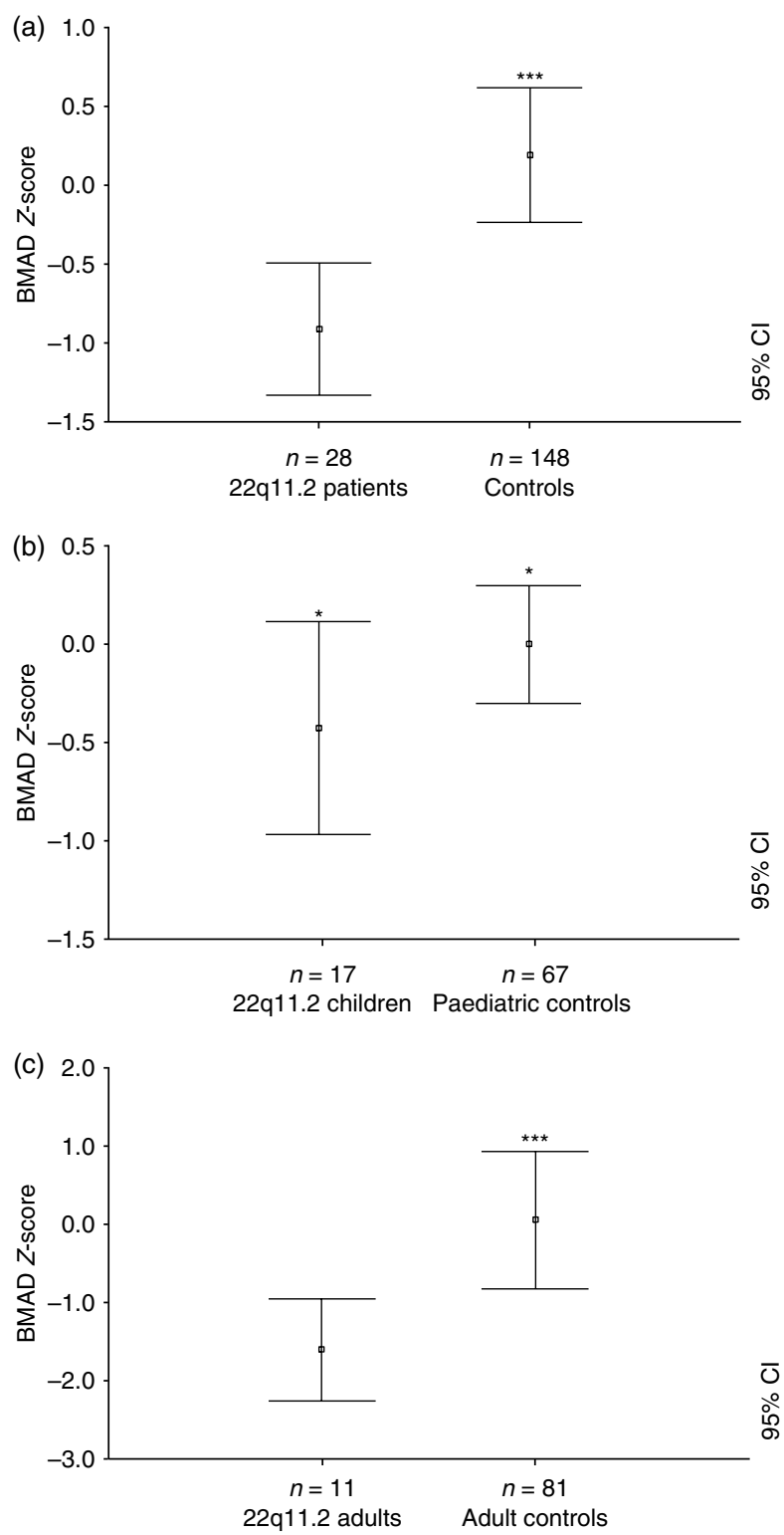

Figure 1 Bone mineral apparent density (BMAD) Z-score in patients with 22q11DS and controls. The figures represent the total group of 22q11DS patients and controls (a), paediatric patients and the relative control group (b), and adult patients and the relative control group (c). ${ }^{\star} P<0.05 ;{ }^{\star \star \star} P<0.001$.

whereas their phosphate levels were normal. Our patients also had significantly lower PTH levels compared with those of the controls $(2.41 \pm 1.22$ vs $3.15 \pm 1.41 \mathrm{pmol} / \mathrm{l} ; \mathrm{P}<0.05)$.

Children and young subjects with 22q11DS showed significantly lower serum osteocalcin levels $(28.62$ \pm 4.71 vs $92.18 \pm 20.83 \mathrm{ng} / \mathrm{ml} ; P<0.001)$ and urinary deoxypyridinoline concentrations $(16.64 \pm 11.53$ vs $42.17 \pm 14.76 \mathrm{nM} / \mathrm{mM}$ creatinine; $P<0.001)$ compared with age-matched controls, but this result was not seen when the adult groups were compared (osteocalcin,
$7.53 \pm 3.12$ vs $8.54 \pm 2.55 \mathrm{ng} / \mathrm{ml} ; P=\mathrm{NS}$; urinary deoxypyridinoline, $9.65 \pm 3.02$ vs $12.93 \pm 4.97 \mathrm{nM} /$ $\mathrm{mM}$ creatinine; $P=\mathrm{NS}$; Figs 2 and 3 respectively). Children and young subjects with 22q11DS also showed significantly lower serum BSAP levels $(57.9 \pm 19.5$ vs $101.8 \pm 28.5 \mathrm{U} / \mathrm{l} ; \quad P<0.001)$ compared with agematched controls, but this result was not seen when the adult groups were compared (BSAP: $13.3 \pm 10.5$ vs $16.5 \pm 8.6 \mathrm{U} / \mathrm{l} ; P=\mathrm{NS}$ ).

Finally, 22q11DS patients who exhibited hypoparathyroidism and/or hypocalcaemia at the time of the study showed significantly lower ionised $(P<0.001)$ and total calcium levels $(P<0.001)$, PTH levels $(P<0.05)$, BSAP levels $(P<0.001)$, osteocalcin levels $(P<0.001)$ and urinary deoxypyridinoline concentrations $(P<0.001)$ compared with patients without hypoparathyroidism and/or hypocalcaemia. Nonetheless, there were no substantial differences in BMAD $Z$-scores between these two groups $(P=N S)$. No differences in BMAD Z-score were also evident when the patients were divided according to the presence of congenital cardiac defects and/or a history of recurrent infections and immunodeficiency $(P=\mathrm{NS})$.

Among the 28 patients, $25(\mathrm{OH}) \mathrm{D}$ values were $<10 \mathrm{ng} / \mathrm{ml}$ (deficient) in none of the patients, $10-20 \mathrm{ng} / \mathrm{ml}$ in 3 patients $(11 \%)$ and $>20 \mathrm{ng} / \mathrm{ml}$ in 25 patients $(89 \%)$, with a mean of $35.1 \pm 17.2 \mathrm{ng} / \mathrm{ml}$ (controls: $30.5 \pm 15.6 \mathrm{ng} / \mathrm{ml}$; $P=\mathrm{NS}$ ). Additionally, $1,25(\mathrm{OH})_{2} \mathrm{D}$ values were also in the normal range in $89 \%$ of patients, with a mean of $51.9 \pm 16.1 \mathrm{pg} / \mathrm{ml}$ (controls: $42.0 \pm 20.7 \mathrm{pg} / \mathrm{ml} ; P<0.05$ ); in the group, one patient showed low $1,25(\mathrm{OH})_{2} \mathrm{D}$ levels $(2.8 \%)$ and two patients showed high $1,25(\mathrm{OH})_{2} \mathrm{D}$ levels $(5.6 \%)$.

The quantitative assessment of physical activity in patients with 22q11DS and controls showed significant differences between the two groups; the percentage of

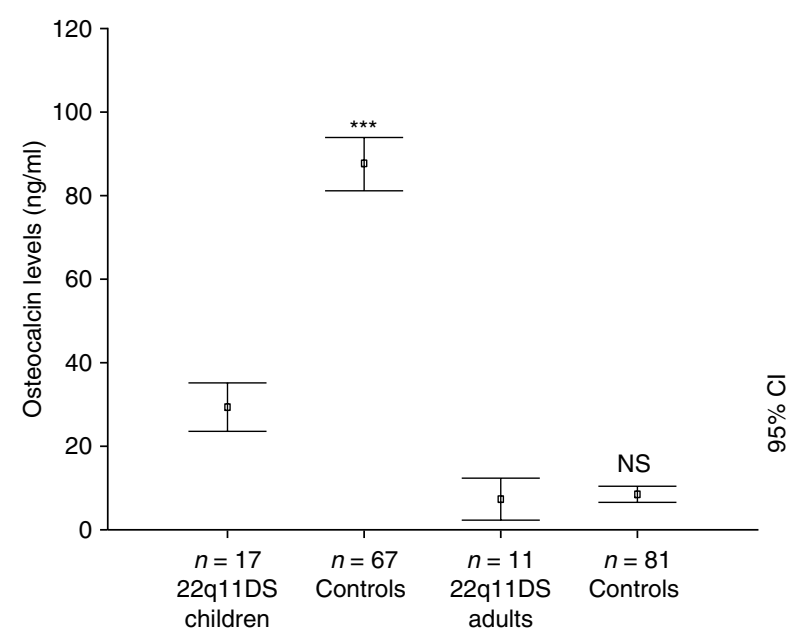

Figure 2 Osteocalcin serum levels $(\mathrm{ng} / \mathrm{ml})$ in patients with 22q11DS and controls. The figure represents paediatric and adult patients and their relative control groups (control groups 1 and 2 respectively). ${ }^{\star \star \star} P<0.001$. 


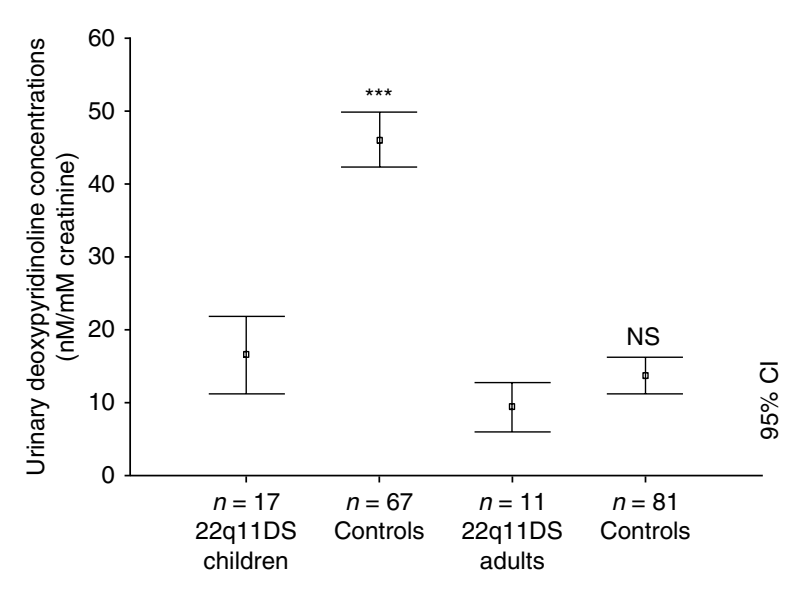

Figure 3 Urinary deoxypyridinoline concentrations (nM for $\mathrm{mM}$ of creatinine) in patients with 22q11DS and controls. The figure represents paediatric and adult patients and their relative control groups (control groups 1 and 2 respectively). ${ }^{\star \star \star} P<0.001$.

current physical activity levels was significantly lower for patients with 22q11DS than for controls $(0 \mathrm{~h} /$ week group 51 and $25 \%$ respectively; $<2 \mathrm{~h} /$ week group 36 and $49 \%$ respectively; $>2 \mathrm{~h} /$ week group 13 and $26 \%$ respectively). Even if the dimensions of the subgroups are limiting for reliable statistical results, there were differences in BMAD Z-score between the patients with a current physical activity level $>2 \mathrm{~h} /$ week and the other groups $(-0.79 \pm 0.86$ vs $-1.36 \pm 0.93 ; P=N S)$. The last group of patients was in better physical condition.

Spearman's rank correlation test showed that in patients with 22q11DS, BMAD Z-score values displayed a significant inverse correlation with age $(r=-0.53$; $P<0.005$; Fig. 4). Both BSAP and osteocalcin levels also showed a significant correlation with total calcium values $(r=0.47 ; P<0.05)$. PTH correlates

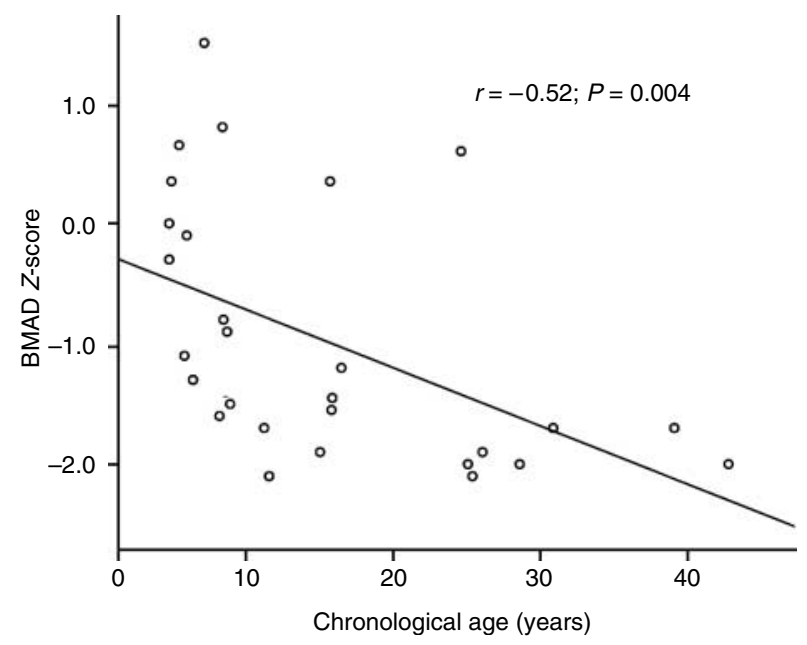

Figure 4 Relationship between bone mineral apparent density $Z$-score values and age (years) $(r=-0.52 ; P<0.005)$ in patients with 22q11DS. significantly with ionised calcium $(r=0.41 ; P<0.05)$ and osteocalcin $(r=0.62 ; P<0.005)$.

The multiple regression analysis included age, sex, PTH, ionised and total calcium levels, phosphate levels, $25(\mathrm{OH}) \mathrm{D}$ and $1,25(\mathrm{OH})_{2} \mathrm{D}$ levels, serum osteocalcin levels, urinary deoxypyridinoline concentrations, quantitative assessment of physical activity, calcium intake and BSAP levels; this analysis did not identify significant predictors of a lower BMAD Z-score.

\section{Discussion}

Our study shows that subjects with 22q11DS have a lower bone mass, probably due to reduced bone modelling during childhood, which may cause a reduced bone mass peak with a significant risk of impaired bone mass in adulthood.

The aetiology of bone impairment in 22q11DS patients may be multifactorial, and we suspect that additional longitudinal data will be necessary to fully ascertain the importance of the many variables that are involved in conditioning a lower bone mass in these patients.

Hypocalcaemia is a frequent manifestation in subjects with 22q11DS, particularly in patients of neonatal age, although it may also be observed later in life (20). This disorder is present in $49-60 \%$ of patients with a confirmed del22q11 (4), and patients with the phenotypic characteristics of the DiGeorge anomaly are more likely to have clinical evidence of hypocalcaemia $(70 \%)$ than patients with VCFS (13-22\%) (21).

This mild or transient hypocalcaemia may frequently be missed because it is probably asymptomatic, and a systematic screening is required for its detection (20). Commonly, however, with an increase in dietary calcium intake, the remaining parathyroid activity supplies sufficient PTH to meet metabolic demands, even if a recurrence of hypoparathyroidism may be precipitated during the periods of increased metabolic demand (18). Therefore, a long-term follow-up should be given to 22q11DS patients with normocalcaemia because of the potential for evolution to hypocalcaemic hypoparathyroidism (22).

A prolonged deficiency in calcium metabolism may cause bone quality alterations (23). Calcium intake has been shown to correlate with bone density in healthy children (23), and maintaining adequate calcium intake during childhood and adolescence is necessary to attain a normal peak bone mass, which may be important in reducing the risk of fractures and osteoporosis later in life (24).

However, reduced levels of physical activity are also considered to be important. From the answers given by patients and/or parents using an activity questionnaire, 22q11DS patients participate in less physical activity than controls. This behaviour may be due to associated disorders such as heart defects or neuropsychological 
impairment. High physical activity has been reported to be associated with high BMD in healthy individuals (25). The effects of physical activity on bone turnover are well known (26). Bone strength is regulated by mechanical loads, especially muscle forces. In children and adolescents, lean body mass and bone mass are highly related (6).

Bone mass accounts for $75-85 \%$ of the variance in the ultimate strength of bone tissue, and a low BMD may lead to an impaired bone mass with an increased risk of fracture (6). Our data, nevertheless, seem to show that 22q11DS patients may not have a significantly greater risk of bone fractures than individuals in the general population.

Bone mass is under strong genetic control, with heritability estimated to be $>50 \%$; this feature is likely determined by complex interactions between genetic and environmental factors throughout fetal development, childhood and adult life (27). Other authors have obtained suggestive evidence for a quantitative trait locus (QTL) affecting lumbar spine BMD variation on chromosomes 22q11-12 (27). The QTL on 22q11 is novel and does not overlap with major QTLs reported by other studies (27).

Therefore, the $22 q 11$ region could be a specific site that is important for conditioning the heritability of a lower BMD in the general population, and, if so, this aspect may explain some of our results.

In 22q11DS patients, BMAD appears to be a useful parameter that can also be utilised to estimate the effective bone density. Correction for weight and height may be necessary because DXA underestimates BMD in short subjects by measuring a real rather than volumetric bone density. In fact, volumetric density has been considered to be a more accurate estimate of bone density in smaller individuals and those with small bones (9). Nevertheless, many previous studies that were conducted in patients with short stature or genetic syndromes associated with short stature did not correct the DXA data, which led to many errors in the interpretation of the results because of false diagnoses of lower bone mass. Today, more attention is paid to this problem, and techniques such as the use of BMAD have allowed researchers to determine a correct BMD for these patients $(9,13)$.

Interestingly, our data show that 22q11DS children and youth have both reduced bone formation (evaluated by the study of the BSAP and osteocalcin) and bone resorption (evaluated by the study of the urinary deoxypyridinoline) markers. These data were not confirmed in adult patients with 22q11DS.

Several studies conducted in both animals and adult humans have shown the presence of increased bone mass in subjects with hypoparathyroidism, although some data obtained from postnatal hypoparathyroid $\left(\mathrm{PTH}^{-/}\right)$animals demonstrated a reduction in bone turnover associated with an increase in trabecular bone volume (28). Therefore, some studies demonstrate a physiological anabolic role for PTH, underpinning its importance in inducing bone accrual (29).

PTH binds to cells of the osteoblastic lineage (28), enhances both bone formation and bone resorption (28), and appears to exert discrete effects on trabecular bone in the intrauterine and postnatal environments (30). PTH contributes to maintenance of normal extracellular fluid calcium levels, at least in part by enhancing trabecular bone resorption (30).

Therefore, we may hypothesise that reduced PTH levels in childhood, even if this phenomenon is frequently latent and may or may not be associated with variable hypocalcaemia, may determine a lower level of bone modelling, which subsequently results in reduced bone accrual and bone mass peak. However, other data, especially long-term data, will be necessary to understand this phenomenon.

This is also of particular importance because childhood is a critical time for bone development and mineralisation (31), and childhood and adolescence are crucial periods of life for the attainment of an optimal bone mass (31). Increases in bone mass and maximal bone mass accrual occur in early mild puberty and slow down in late puberty (32).

A reduced bone accrual may predispose subjects with 22q11DS to a higher risk for impaired bone mass later in life, differentiating the results of a congenital hypoparathyroidism from those of a secondary and acquired hypoparathyroidism, especially at the onset of adulthood.

In conclusion, the present study indicates that subjects with 22q11DS have a significant reduction in bone mass, particularly in adulthood. Furthermore, bone metabolism appears to be altered in these patients, especially in the paediatric age groups. We therefore speculate that factors associated with deletion of 22q11, for example hypoparathyroidism, hypocalcaemia, reduced physical activity, presence of cardiac defects or recurrent infections, may cause reduced bone remodelling and bone mass. Therefore, we suggest that bone mass and metabolism in 22q11DS patients should be closely monitored. More studies are needed to confirm our data and to evaluate eventual treatments that may ameliorate the bone mass peak and reduce the risk of osteoporosis in patients with this syndrome.

\section{Declaration of interest}

The authors declare that there are no conflicts of interest that could be perceived as prejudicing the impartiality of the research reported herein.

\section{Funding}

This research did not receive any specific grant from any funding agency in the public, commercial or not-for-profit sector. 


\section{Acknowledgements}

The authors are grateful to Dr Giampiero Igli Baroncelli (University of Pisa) for his useful help and counselling.

\section{References}

1 Oskarsdottir S, Vujic M \& Fast A. Incidence and prevalence of the 22q11 deletion syndrome: a population-based study in Western Sweden. Archives of Disease in Childhood 200489 148-151.

2 Yamagishi H \& Srivastava D. Unraveling the genetic and developmental mysteries of 22q11 deletion syndrome. Trends in Molecular Medicine 20039 383-389.

3 Robin N \& Shprintzen R. Defining the clinical spectrum of deletion 22q11.2. Journal of Pediatrics 2005 147 90-96.

4 Ryan AK, Goodship JA, Wilson DI, Philip N, Levy A, Seidel H, Schuffenhauer S, Oechsler H, Belohradsky B, Prieur M, Aurias A, Raymond FL, Clayton-Smith J, Hatchwell E, McKeown C, Beemer FA, Dallapiccola B, Novelli G, Hurst JA, Ignatius J, Green AJ, Winter RM, Brueton L, Brondum-Nielsen K, Stewart F, Van Essen T, Patton M, Paterson J \& Scambler PJ. Spectrum of clinical features associated with interstitial chromosome 22q11 deletions: a European collaborative study. Journal of Medical Genetics 199734 798-804.

5 Brauner R, Le Harivel de Gonneville A, Kindermans C, Le Bidois J, Prieur M, Lyonnet S \& Souberbielle JC. Parathyroid function and growth in 22q11.2 deletion syndrome. Journal of Pediatrics 2003 142 504-508.

6 Schoenau E, Land C, Stabrey A, Remer T \& Kroke A. The bone mass concept: problems in short stature. European Journal of Endocrinology 2004151 (Suppl 1) S87-S91.

7 Katzman DK, Bachrach LK, Carter DR \& Marcus R. Clinical and anthropometric correlates of bone mineral acquisition in healthy adolescent girls. Journal of Clinical Endocrinology and Metabolism 199173 1332-1339.

8 Kröger H, Kotaniemi A, Vainio P \& Alhava E. Bone densitometry of the spine and femur in children by dual-energy X-ray absorptiometry. Bone and Mineral 199217 75-85.

9 de Lind van Wijngaarden RF, Festen DA, Otten BJ, van Mil EG, Rotteveel J, Odink RJ, van Leeuwen M, Haring DA, Bocca G, Mieke Houdijk EC \& Hokken-Koelega AC. Bone mineral density and effects of growth hormone treatment in prepubertal children with Prader-Willi syndrome: a randomized controlled trial. Journal of Clinical Endocrinology and Metabolism 200994 3763-3771.

10 Boot AM, Engels MA, Boerma GJ, Krenning EP \& De Muinck Keizer-Schrama SM. Changes in bone mineral density, body composition, and lipid metabolism during growth hormone (GH) treatment in children with GH deficiency. Journal of Clinical Endocrinology and Metabolism 199782 2423-2428.

11 Willemsen RH, Arends NJ, Bakker-van Waarde WM, Jansen M, van Mil EG, Mulder J, Odink RJ, Reeser M, Rongen-Westerlaken C, Stokvis-Brantsma WH, Waelkens JJ \& Hokken-Koelega AC. Longterm effects of growth hormone (GH) treatment on body composition and bone mineral density in short children born small-for-gestational-age: six-year follow-up of a randomized controlled GH trial. Clinical Endocrinology 200767 485-492.

12 Walther F, Fusch C, Radke M, Beckert S \& Findeisen A. Osteoporosis in pediatric patients suffering from chronic inflammatory bowel disease with and without steroid treatment. Journal of Pediatric Gastroenterology and Nutrition 200643 42-51.

13 Benbassat CA, Eshed V, Kamjin M \& Laron Z. Are adult patients with Laron syndrome osteopenic? A comparison between dualenergy X-ray absorptiometry and volumetric bone densities Journal of Clinical Endocrinology and Metabolism $2003 \mathbf{8 8}$ 4586-4589.

14 Galluzzi F, Stagi S, Salti R, Toni S, Piscitelli E, Simonini G, Falcini F \& Chiarelli F. Osteoprotegerin serum levels in children with type 1 diabetes: a potential modulating role in bone status. European Journal of Endocrinology 2005153 879-885.
15 Nicoletti I. Normal and Pathological Auxology, pp 289-304. Firenze: Centro Studi Auxologici, 1994.

16 Greulich WW \& Pyle SI. Radiographic Atlas of Skeletal Development of the Hand and Wrist, edn 2. Stanford Univ. Press: Stanford, CA, USA 1959.

17 Tanner JM \& Whitehouse RH. Clinical longitudinal standards for height, weight height velocity, weight velocity and stages of puberty. Archives of Disease in Childhood 197651 170-179.

18 Weinzimer SA. Endocrine aspects of the 22q11.2 deletion syndrome. Genetics in Medicine 20013 19-22.

19 Kroger H, Vainio P, Nieminen J \& Kotaniemi A. Comparison of different models for interpreting bone mineral density measurements using DXA and MRI technology. Bone 199517 157-159.

20 Cuneo B, Driscoll D, Gidding S \& Langman C. Evolution of latent hypoparathyroidism in familial 22q11 deletion syndrome. American Journal of Medical Genetics 199769 50-55.

21 McDonald-McGinn DM, Kirschner R, Goldmuntz E, Sullivan K, Eicher P, Gerdes M, Moss E, Solot C, Wang P, Jacobs I, Handler S, Knightly C, Haher K, Wilson M, Ming JE, Grace K, Driscoll D, Pasquariello P, Randall P, Larossa D, Emanuel BS \& Zackai EH. The Philadelphia story: the $22 \mathrm{q} 11.2$ deletion: report on 250 patients. Genetic Counseling 199910 11-24.

22 Hiéronimus S, Bec-Roche M, Pedeutour F, Lambert JC, WagnerMalher K, Mas JC, Sadoul JL \& Fénichel P. The spectrum of parathyroid gland dysfunction associated with the microdeletion 22q11. European Journal of Endocrinology 2006155 47-52.

23 Ruiz JC, Mandel C \& Garabedian M. Influence of spontaneous calcium intake and physical exercise on the vertebral and femoral bone mineral density of children and adolescents. Journal of Bone and Mineral Research 199595 675-679.

24 NIH Consensus conference. Optimal calcium intake. NIH Consensus Development Panel on Optimal Calcium Intake. Journal of the American Medical Association 1994272 1942-1948.

25 Karlsson MK, Linden C, Karlsson C, Johnell O, Obrant K \& Seemann E. Exercise during growth and bone mineral density and fractures in old age. Lancet 2000355 469-470.

26 Karlsson KM, Karlsson C, Ahlborg HG, Valdimarsson O, Ljunghall S \& Obrant KJ. Bone turnover responses to changed physical activity. Calcified Tissue International 2003 72 675-680.

27 Kaufman JM, Ostertag A, Saint-Pierre A, Cohen-Solal M, Boland A, Van Pottelbergh I, Toye K, de Vernejoul MC \& Martinez M. Genome-wide linkage screen of bone mineral density (BMD) in European pedigrees ascertained through a male relative with low BMD values: evidence for quantitative trait loci on 17q21-23, 11q12-13, 13q12-14, and 22q11. Journal of Clinical Endocrinology and Metabolism 200893 3755-3762.

28 Miao D, Li J, Xue Y, Su H, Karaplis AC \& Goltzman D. Parathyroid hormone-related peptide is required for increased trabecular bone volume in parathyroid hormone-null mice. Endocrinology 2004 $1453554-3562$.

29 Horwitz MJ, Tedesco MB, Gundberg C, Garcia-Ocana A \& Stewart AF. Short-term, high-dose parathyroid hormone-related protein as a skeletal anabolic agent for the treatment of postmenopausal osteoporosis. Journal of Clinical Endocrinology and Metabolism $2003 \mathbf{8 8} 569-575$.

30 Gunther T, Chen ZF, Kim J, Priemel M, Rueger JM, Amling M, Moseley JM, Martin TJ, Anderson DJ \& Karsenty G. Genetic ablation of parathyroid glands reveals another source of parathyroid hormone. Nature 2000406 199-203.

31 Bachrach L. Acquisition of optimal bone mass in childhood and adolescence. Trends in Endocrinology and Metabolism 200112 $22-28$.

32 Mora S \& Gilsanz V. Establishment of peak bone mass. Endocrinology and Metabolism Clinics of North America 200332 39-63.

Received 6 May 2010

Accepted 1 June 2010 